Presented at:

Fourth Annual

BNL- -47862

1992 International Industrial Symposium

DE93 005530

on the Super Collider (IISSC)

New Orleans, Louisiana

March 4-6, 1992

\title{
INVESTIGATION OF AZIMUTHAL STRESSES DUE TO WELDING AND COOLDOWN*
}

\author{
Melvin Lindner and Steve Mulhall \\ Brookhaven National Laboratory \\ 17 Cornell Avenue \\ Building 902A \\ Upton, New York 11973
}

\section{INTRODUCTION}

For some time, it has been known that a prestress in the cold mass skin surrounding the yoke was desirable for the prevention of unwanted "loose" coil effects on the performance of magnets. From practical experience, it was determined that the hoop stresses developed by seam welding were adequate to provide the desired preload on the coils.

The tests reported here were intended to:

1. Determine the stresses developed by welding.

2. Attempt to determine the friction coefficient between the yoke laminations and the stainless steel shell.

3. Determine the effects of repeated cooldown cycles on the stresses in the shell.

\section{TEST PROCEDURE}

An 18 inch long model of a dipole was constructed using laminations, collaring keys, coil sections and precision rolled Type 304 stainless steel shells, as similar as possible to the actual configuration of typical dipole magnets constructed at BNL. Strain gauges were attached to half the outside surface of the skin at the mid-point of the model, at intervals of 15 degrees, and the strains at these points were recorded.

The test procedure consisted of welding the skins in the same sequence as the assembly practice for complete magnets. The skin halves were first clamped around the assembled core components, and the strain gauges zeroed to establish a baseline.

*Work supported by the U.S. Department of Energy

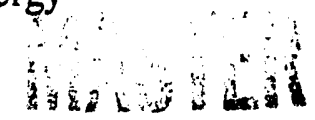


TIG welding procedures were used for all welding operations, and strain readings were taken at all logical steps in the welding sequence. Readings were taken after tack welding of the shells, after the root welding pass, and after the fill pass. The weld seams were then smoothed, and strain gauges were attached on the weld seams. Reference strain gauges were bonded to unstressed pieces of 304 stainless steel to establish the tempierature correction for the gauge readings.

After all welding operations were completed and the strain readings recorded, the model was lowered into a container and covered with liquid nitrogen. Strain readings were taken after the temperature of the model stabilized. The nitrogen was then allowed to evaporate, and readings were taken after the model stabilized at room temperature. The cycles were repeated for a total of three cycles, and readings were taken after each half cycle. At the conclusion of the temperature cycles, the skin was cut open at the mid-point of the uninstrumented side of the model, and residual strain readings were taken to determine if there was plastic deformation of the shell. No attempt was made to determine longitudinal strains.

\section{RESULTS}

The plotted data of Figure 1 show the strains as measured after the indicated steps in the experiment. The model behaved very nearly as expected, and the recorded data showed good correlation from cycle to cycle. As expected, there was some slight shift during the first cooldown cycle, but the changes were not repeated during subsequent cycle. .

Some anomalies were found in that the measurement did not follow a smooth curve, but this is attributed to small deviations in the shape of the shell. Large data scatter is apparent at the 0 degree weld position, but this was found to be due to a local distortion of the shell at that point. The shell showed a small flat configuration, rather than a smooth radius, that put the weld seam into bending rather than tension. Data scatter at this point made this one gauge unreliable. The readings on the gauge at the 180 degree point showed good repeatability and are considered valid. A free condition strain reading at this seam indicates that plastic deformation occurred at some time during the tests. Since it was not possible to instrument the weld seam during welding, it is an educated guess that the deformation was caused by stress levels beyond yield at cooldown, most likely during the first cycle, since the experimental data does repeat in subsequent cycles.

The strain data was converter to stress using the stress-strain diagrams of Figure 2, and is plotted in Figure 3. Accurate data regarding low temperature stress-strain relationship is hard to find, and the curve shown was derived from elastic modulus and yield strength data.

Curve fitting techniques using the relationship:

$$
\mathrm{T}_{\mathrm{o}} / \mathrm{T}=\mathrm{e}^{\mathrm{i} \alpha}
$$

with tensile inputs $\left(\mathrm{T}_{\mathrm{o}}\right)$ applied at two places diametrically opposite, were used to derive 
friction coefficient effects, and a coefficient of between 1.0 and 1.2 appears to be appropriate. This value corresponds to values given in several reference books for dry steelto-ste 1 combinations, and is reasonable considering the clean and dry components and the effects of the fine blanked lamination texture rubbing on the stainless steel surface.

\section{CONCLUSIONS}

Azimuthal (hoop) stresses in the shell vary with azimuthal position around the shell. This variation is directly correlated to the coefficient of friction between the shell and the laminations. The stresses are generated by shrinkage during the welding operations, and are increased by differential thermal contraction during cooldown. Stresses on the order of 35 $40 \mathrm{KSI}$ are easily obtained at room temperature, and may rise to $45 \mathrm{KSI}$ at low temperatures. Extrapolated data indicates that weld seam friction coefficient estimate, derived from the experimental data, may be used as an input for the ANSYS analysis of the yoke and skin of the magnet assemblies.

\section{ACKNOWLEDGEMENTS}

The authors gratefully acknowledge the constructive suggestions made by M. Rehak and $R$. Shutt with regard to analysis of the data, and to R. Jackimowicz for doing the experimental work.

\section{DISCLAIMER}

\footnotetext{
This report was prepared as an account of work sponsored by an agency of the United States Government. Neither the United States Government nor any agency thereof, nor any of their employees, makes any warranty, express or implied, or assumes any legal liability or responsibility for the accuracy, completeness, or usefulness of any information, apparatus, product, or process disciosed, or represents that its use would not infringe privately owned rights. Reference herein to any specific commercial product, process, or service by trade name, trademark, manufacturer, or otherwise does not necessarily constitute or imply its endorsement, recommendation, or favoring by the United States Government or any agency thereof. The views and opinions of authors expressed herein do not necessarily state or reflect those of the United States Government or any agency thereof.
} 

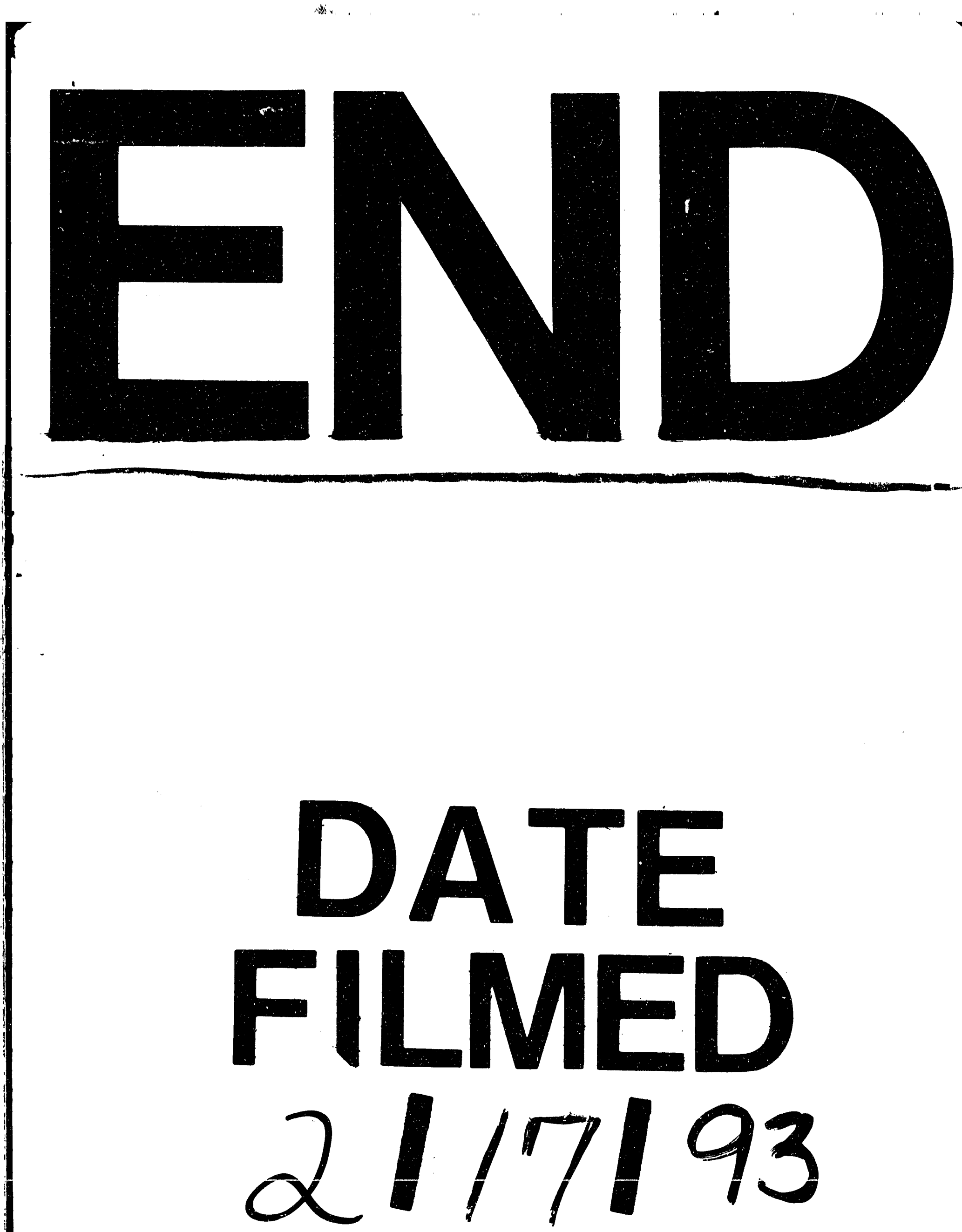


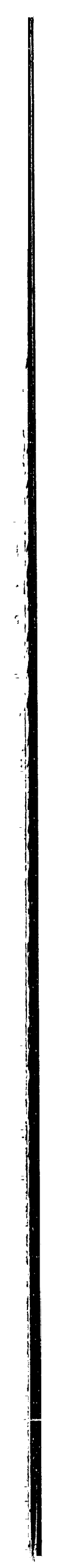

